\title{
A CRISE ECONÔMICA NO BRASIL E SEUS EFEITOS PARA O SETOR DE SERVIÇOS DE REPARO E MANUTENÇÃO
}

\section{THE ECONOMIC CRISIS IN BRAZIL AND ITS EFFECTS ON THE REPAIR AND MAINTENANCE SERVICES SECTOR}

\author{
Rodrigo Miguel dos Santos ${ }^{1 *}$, Edson Trajano Vieira ${ }^{2}$. \\ ${ }^{1}$ Engenheiro Eletricista, Universidade de Taubaté, Taubaté, SP, Brasil, eng.rodrigomiguel@gmail.com. \\ ${ }^{2}$ Doutor em História Econômica, Universidade de Taubaté, Taubaté, SP, Brasil, etrajanov@gmail.com.
}

\section{Resumo}

A economia brasileira passou por um período de crescimento entre os anos de 2004 e 2013, em que o governo federal adotou políticas públicas que permitiram a redução da pobreza e da miséria, o aumento do emprego formal e o aumento da renda e do crédito. O encadeamento desses indicadores modificou o modelo de vida dos brasileiros, elevando o seu padrão de consumo e favorecendo a aquisição de bens duráveis. Entretanto, a recessão econômica que atingiu o país entre os anos de 2015 e 2016 trouxe consequências evidentes para diversos setores do mercado brasileiro. O objetivo desse trabalho é analisar os efeitos da crise econômica no Brasil para o setor de serviços de reparo e manutenção. O método utilizado para análise de dados foi a regressão através da utilização de linhas de tendências gráficas lineares. Os resultados demonstraram que as consequências negativas da crise econômica sobre a taxa de desocupação e o rendimento do trabalhador culminaram com a redução do consumo de bens duráveis pelas famílias brasileiras. Esse fato favoreceu o fortalecimento do mercado de reparação e manutenção no país, sendo a tendência total obtida para o crescimento com incremento de aproximadamente $10,6 \%$ na receita operacional líquida do setor entre os anos de 2014 e 2017. Como conclusão, verifica-se que a análise associativa realizada permitiu a obtenção de resultados satisfatórios do comportamento do mercado em estudo, possibilitando a delimitação de tendências para o setor conforme a situação econômica corrente.

Palavras-chave: Crise Econômica. Serviços de Reparo e Manutenção. Análise de Regressão. Linhas de Tendência.

\begin{abstract}
The Brazilian economy went through a period of growth between 2004 and 2013, in which the federal government adopted public policies that allowed the reduction of poverty and misery, the increase in formal employment and the increase in income and credit. The chaining of these indicators has changed the life model of Brazilians, raising their consumption pattern and favoring the acquisition of durable goods. However, the economic recession that hit the country between 2015 and 2016 brought evident consequences for several sectors of the Brazilian market. The objective of this work is to analyze the effects of the economic crisis in Brazil for the sector of repair and maintenance services. The method used for data analysis was regression through the use of linear graphic trend lines. The results show that the negative consequences of the economic crisis on the unemployment rate and the income of the worker culminated in the reduction of consumption of durable goods by Brazilian families. This fact favored the strengthening of the repair and maintenance market in the country, with the total trend obtained for growth with an increase of approximately $10.6 \%$ in the net operating revenue of the sector between the years 2014 and 2017. As a conclusion, it is verified that the associative analysis carried out allowed to obtain satisfactory results of the behavior of the market under study, enabling the delimitation of trends for the sector according to the current economic situation.
\end{abstract}

Keywords: Economic crisis. Repair and Maintenance Services. Regression analysis. Trend Lines.

(C)UNIS-MG. All rights reserved. 
How to cite this article:

SANTOS, Rodrigo Miguel; VIEIRA, Edson Trajano. A crise econômica no brasil e seus efeitos para o setor de serviços de reparo e manutenção. Interação, Varginha, MG, v. 22, p. 146 - 161, 2020. ISSN 1517-848X / ISSN $2446-9874$.

Disponível em: http://periodicos.unis.edu.br/index.php/interacao/article/view/384

DOI: https://doi.org/10.33836/interacao.v22i1.384

\section{INTRODUÇÃO}

De acordo com Melo (1998), o setor de serviços passou a ser objeto de consideração na análise econômica a partir da década de 1930, sendo denominados primariamente como atividades econômicas terciárias, pois era o segmento caracterizado pela produção de bens imateriais. Em 1940, Colin Clark propôs a denominação de "Serviços" para o setor devido à grande abrangência de atividades nele incluídas. Essa variedade de atividades e as suas características de execução distintas trazem dificuldades para mensuração estatística do produto dos serviços e revelam uma base estatística pouco disponível.

O mercado de serviços na economia nacional e mundial tem crescido significativamente, o que demonstra o desenvolvimento da sociedade contemporânea que necessita de serviços tradicionais e diferenciados (CALARGE, 2016). Isso permite oportunidades de reinserção no mercado de trabalho e de empreender, tendo em vista que estas atividades geralmente não necessitam de grandes aportes iniciais de investimento.

Com a ocorrência de uma crise econômica e todos os efeitos dela provenientes, tem-se uma tendência do consumidor de reduzir seus gastos, focando nas suas necessidades principais. Assim a aquisição de bens duráveis fica em segundo plano, e se busca aproveitar os bens que já estão em posse, oferecendo-lhes as condições de manutenção necessárias. A influência econômica e o comportamento setor de serviços de reparo e manutenção não é alvo de muitos estudos, permitindo uma grande gama a ser explorada. Desta forma, o objetivo geral desse trabalho é analisar os efeitos da crise econômica no Brasil para o setor de serviços de reparo e manutenção.

\section{FUNDAMENTAÇÃO TEÓRICA}

\subsection{Crise Econômica}

A economia brasileira passou por um período de crescimento entre os anos de 2004 a 2013, em que, de acordo com Paula (2017) foi em média de 4,0\% ao ano. No mesmo período, ocorreu também uma melhoria no processo de distribuição de renda e redução da pobreza. $A$ partir do segundo trimestre de 2014 o país passou a encarar uma forte e prolongada recessão que perdurou até o quarto trimestre de 2016 (IPEA, 2019b).

A recessão econômica é descrita como uma fase de contração do ciclo econômico, caracterizada como dois ou mais trimestres consecutivos de queda no Produto Interno bruto (PIB), ou seja, redução do nível de produção. As consequências desse período são materializadas através do aumento do desemprego, queda na renda familiar, redução do consumo, redução das taxas de lucro, aumento no número de empresas que declaram falência e concordata, e queda no número de investimentos no país (RECESSÃO, 2019).

O PIB é um indicador na macroeconomia, que tem por objetivo principal mensurar a atividade econômica de uma região. Caracteriza-se pela a soma de todos os bens e serviços finais produzidos por um país, estado ou cidade, durante um período. O referido indicador mede apenas 
os bens e serviços finais para evitar a dupla contagem, sendo classificado em nominal ou real (IBGE, 2019f). O PIB nominal é calculado a preços correntes no ano em que o bem ou serviço foi produzido e comercializado. O PIB real é calculado a preços constantes, onde é escolhido um ano base para eliminar o efeito da inflação, sendo este indicador o mais indicado para análises (BASTOS, 2017).

Ao realizar a quantização do PIB de uma região levam-se em conta os componentes de demanda agregada, caracterizados pelo conjunto de todos os gastos realizados pelos agentes participantes do PIB. De acordo com Fevereiro (2016), as contribuições dos componentes da demanda final são segmentadas por: consumo das famílias; consumo do governo; investimento; e importações.

Os investimentos realizados em uma região são de natureza pública ou privada. De acordo com Andrade (2017), a crise econômica iniciada no país no ano de 2015 é principalmente financeira, o que é evidenciado pela ausência de investimentos no país. As empresas privadas não tem interesse em investir capital em países que estão passando por sérias dificuldades, por razões da redução do crédito bancário, mas principalmente em função dos retornos econômicos inconsistentes, resultantes da redução do consumo. As causas da diminuição do consumo de bens duráveis são evidenciadas em tempos de crise financeira, pois decorrem de um efeito culminante do aumento do desemprego, redução do crédito e renda do trabalhador.

\subsection{Desemprego e Redução dos Rendimentos do Brasileiro}

A corrente disparidade entre a evolução da demanda e a oferta de trabalhadores no mercado de trabalho demonstra o crescimento recente do desemprego no país, em que sua determinação se encontra associada à contração do ciclo econômico nacional ocorrido entre os anos de 2015 e 2016 (POCHMANN, 2016).

Devido ao encerramento de muitas empresas, ocorreu uma grande queda no número de postos de trabalho no país nos últimos cinco anos, culminando no desemprego. $O$ brasileiro encontra dificuldades para se recolocar no mercado de trabalho, demorando mais tempo para que isso ocorra. É um estado complicado até mesmo para aquele que se encontra empregado, pois o corte de efetivo tem sido uma política adotada por empresas para amortecer custos para enfrentar a crise (ANDRADE, 2017).

Andrade (2017) descreve a globalização e a inovação tecnológica inserida por esses como dois fatores causadores agregados do desemprego. O processo de globalização é uma etapa do desenvolvimento do capitalismo mundial, realizando a quebra de barreiras alfandegárias, o rompimento de limites territoriais entre Estados, a facilitação entre o trânsito de pessoas, serviços, capitais, bens e recursos tecnológicos. O principal efeito desse fenômeno para a redução do emprego no país foi no processo precoce de desindustrialização que rapidamente destrói ocupações assentadas direta e indiretamente na produção e bens manufaturados (POCHMANN, 2018).

Sobretudo em períodos de crise econômica, novas discussões são levantadas a respeito dos reais causadores de desemprego. Discutido por Mattoso (2000), a relação entre inovação tecnológica e desemprego demonstra-se conflituosa. Em termos microeconômicos analisando uma empresa, setor ou região, o progresso técnico pode refletir na supressão de empregos. Ao analisar os efeitos macroeconômicos ou nacionais da inovação tecnológica e da produtividade proporcionada por esta, ao mesmo tempo que destroem produtos, empresas, e empregos, também criam novos e até mesmo desenvolvem novos setores ou atividades econômicas. Em 
suma, embora possa modificar a determinação do nível ocupação, a inovação tecnológica não pode ser delimitada somente pelo impacto inicial seu resultado.

De acordo com Montali (2016), outro acontecimento que afetou a demanda de emprego e a remuneração do brasileiro foi o processo de reestruturação produtiva decorrido na década de 90, que mudou o padrão de incorporação da força de trabalho. Esse fato gerou maiores restrições à absorção em trabalhos assalariados regulamentados e maiores inserções como autônomos, seja ela pela terceirização ou pela iniciativa do trabalho por conta própria. Desta forma, isso resultou além da redução das remunerações, também na precarização dos vínculos e na perda proteção oferecida pelos direitos trabalhistas.

Aliado ao exposto as transformações econômicas de uma região afetam diretamente o mercado e as condições de trabalho. O desemprego causado pela retração econômica do país gera um aumento na força de trabalho disponível no mercado. Assim, de acordo com a "lei da oferta e procura", quando a oferta de emprego é menor que a procura, os critérios de seleção dos candidatos tornam-se mais rigorosos, os investimentos em benefícios sociais reduzem, deixa-se de ter competições das organizações pelo mercado de recursos humanos e aumenta a competição entre os candidatos, por fim os salários oferecidos pelos cargos são mais baixos (NUNES, 2016).

\subsection{Consumo de Bens Duráveis e o Mercado de Serviços de Reparo e Manutenção no País}

De acordo com Earp (2014, p. 473): "a difusão de bens de consumo duráveis costuma ocorrer em ondas, começando das camadas de renda mais alta e progressivamente se espraiando para grupos de menor poder aquisitivo". Desta forma, a evolução das vendas de bens duráveis depende crucialmente da distribuição de renda. Os ganhos de produtividade da indústria dependem do aumento de seu mercado consumidor, assim após atingir as vendas possíveis aqueles de detém maior poder aquisitivo o próximo passo consiste em fazer com que seus produtos atinjam também os consumidores de menor renda.

Descrito por Rossi (2017), o período entre 2002 e 2013 foi marcado pela adoção do governo federal de políticas públicas para a redução da pobreza e da miséria, aumento do emprego formal, aumento da renda e do crédito, além da redução do desemprego. Os dois últimos tópicos elencados são os responsáveis pelo salto no consumo da população de bens duráveis, sejam eles bens pessoais e domésticos, equipamentos de informática e comunicação, ou veículos automotores. Como exemplo, têm-se o aumento de 28,2\% em 2003 para 44,4\% em 2012 no acesso das famílias brasileiras a bens duráveis como telefone, televisão, fogão, geladeira, rádio e máquina de lavar.

O consumo de bens duráveis em uma região é diretamente afetado pelo rendimento financeiro da população que a ocupam, desta forma quando a disposição de bens monetários cai, o consumo também reduz. Para mensurar a real situação do consumo de bens duráveis do país, os dados utilizados provêm da Pesquisa Industrial Mensal - Produção Física (PIM-PF), que fornece indicadores de curto prazo para comportamento real da produção industrial segmentada no país desde 1970. Esse parâmetro também é conhecido como Indicador Mensal de Consumo Aparente de Bens Industriais definido como a produção industrial interna acrescida das importações (IPEA, 2019a).

O efeito mundial da globalização foi potencializado por meio de inovações tecnológicas como a fibra ótica, combinada com lasers e satélites. Esses fatos revolucionaram a mídia das telecomunicações de maneira que pessoas de todos os continentes passaram a ser influenciadas 
pela internet, impactando em grandes mudanças em seus estilos de vida. A troca de informações proporcionada favoreceu também a globalização industrial, em que foram desenvolvidos novos produtos de baixo custo, como celular, computador e televisão, criando um mercado de consumo em massa de bens duráveis (CARVALHO, 2019).

A alteração nos padrões de vida e consumo dos brasileiros influenciado pela globalização e políticas econômicas favoráveis correntes até meados de 2013 , fez com que a maioria dos lares passasse a dispor de bens de duráveis até então não acessíveis na década de 90 . Segundo IBGE (2019g), o acesso dos bens duráveis é segmentado em: objetos pessoais e domésticos, equipamentos de informática e comunicações e veículos automotores. A partir da Tabela 1 é possível inferir a disponibilidade de bens duráveis comuns na família dos brasileiros para o ano de 2017, o fogão sendo um item doméstico não fornecido pela Pesquisa Nacional por Amostra de Domicílios Contínua (PNAD), é um equipamento que de acordo com as séries históricas atingiu praticamente a totalidade dos lares brasileiros, por isso já não é mais citado nas pesquisas.

Tabela 1 - Disponibilidade de Bens Duráveis por Segmento nos Domicílios Brasileiros

\begin{tabular}{|c|c|c|}
\hline SEGMENTO & ITEM & $\begin{array}{l}\text { (\%) DE DOMICÍLIOS } \\
\text { COM ACESSO }\end{array}$ \\
\hline \multirow{3}{*}{ Objetos Pessoais e Domésticos } & Geladeira & 98,1 \\
\hline & Máquina de Lavar Roupa & 63,8 \\
\hline & Televisão & 96,8 \\
\hline \multirow{2}{*}{$\begin{array}{l}\text { Equipamentos de Informática } \\
\text { e Comunicações }\end{array}$} & Telefone Móvel Celular & 92,7 \\
\hline & Microcomputador & 44,0 \\
\hline \multirow{2}{*}{ Veículos Automotores } & Automóvel & 47,6 \\
\hline & Motocicleta & 22,4 \\
\hline
\end{tabular}

Fonte: Adaptado IBGE, 2019c.

Analisando a Tabela 1 é possível constatar que principalmente no segmento de objetos pessoais e domésticos há uma grande disponibilidade nos lares brasileiros, sendo seguido pelo segmento de equipamentos de informática e comunicações que apresenta um índice de posse aparelhos móveis de comunicação de $92,7 \%$. Para o setor de veículos automotores há uma posse de 47,6 \% de automóveis, que representaram para o ano de 2017 uma frota nacional de aproximadamente 53 milhões de automóveis. Para o ano de 2017 a disponibilidade de motocicletas por lares brasileiros foi de $22,4 \%$, caracterizando uma frota nacional de aproximadamente 22 milhões de motos (IBGE, 2019a).

Sendo muitas vezes o único meio de transporte para o deslocamento, os automóveis necessitam de manutenções corretivas e programadas. As intervenções programadas permitem utilizar os veículos em suas melhores condições, em média a cada seis meses é necessário realizar uma intervenção de rotina em um automóvel, relacionadas principalmente a sistemas de lubrificação, rodagem e freios. A frequência de manutenção dos veículos provoca a movimentação econômica das oficinas especializadas.

O ciclo de vida e a periodicidade de manutenção e reparo de determinados bens permitem a sua utilização por um maior ou menor tempo. De acordo com Moulin (2015), como ferramenta de mercado para estimular o consumo, a obsolescência programada de alguns produtos passou a 
ser uma medida utilizada pelos fabricantes. O gráfico da Figura 1 apresenta expectativa do consumidor contra o tempo médio real de posse de alguns bens duráveis.

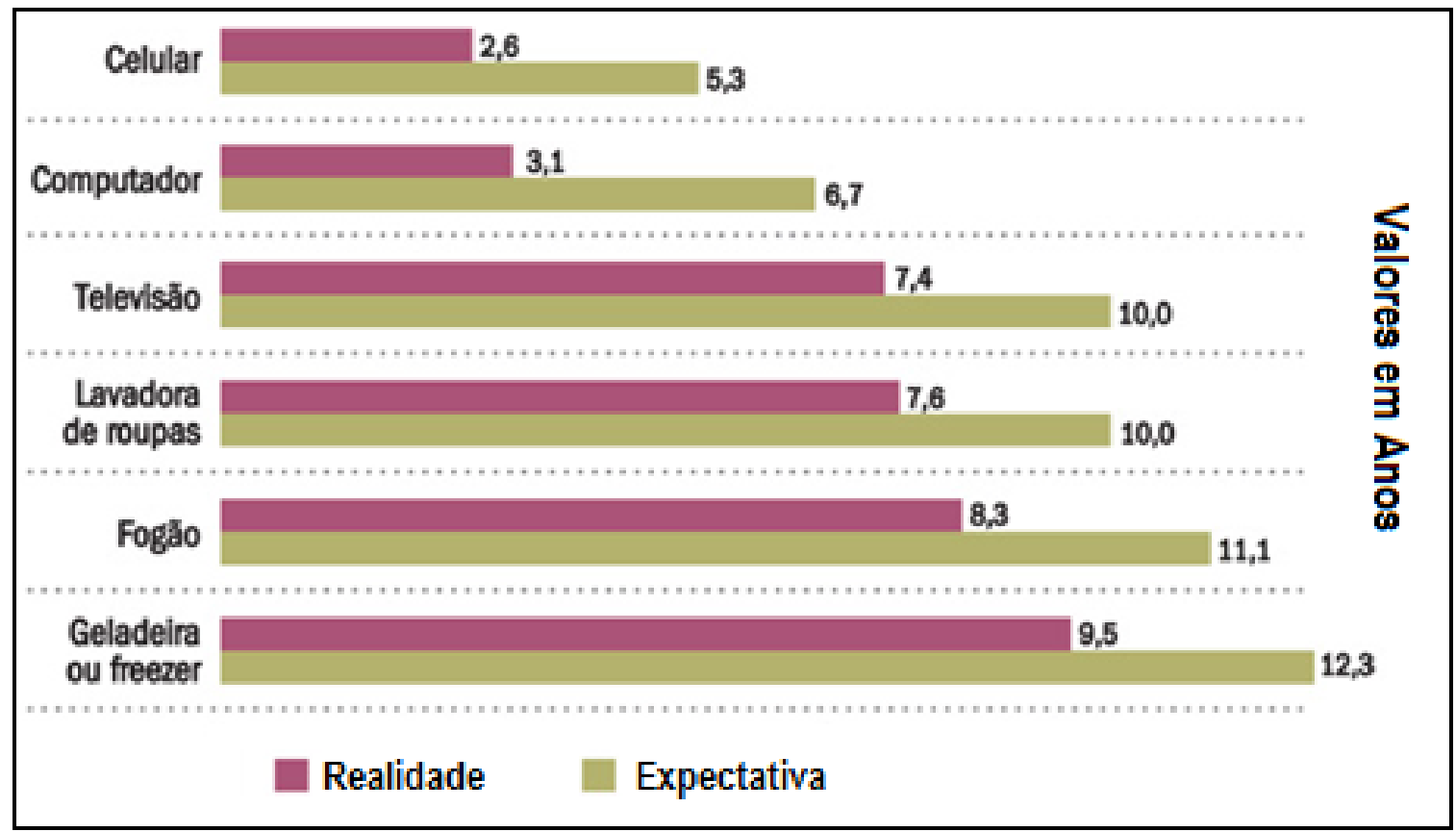

Fonte: Moulin, 2015.

Figura 1 - Tempo Médio Real de Posse versus Expectativa do Consumidor (em Anos)

Conforme exposto, dada a grande massa de bens duráveis disponível nos lares dos brasileiros e a redução do poder de substituição destes devido aos agravamentos proporcionados pela recessão econômica que atingiu o país, o consumidor optou pela conservação dos bens que possui, seja qual for o segmento deste. Conforme a Figura 1, observa-se que apesar do real tempo de uso de determinados aparelhos domésticos e de comunicação serem menores do que o esperado, eles permitem longos intervalos até a sua substituição, isso se torna possível por meio da busca do consumidor por serviços de reparo e manutenção como alternativa mais viável para manter o seu patrimônio operante.

\section{METODOLOGIA}

O método empregado neste trabalho foi à análise gráfica de indicadores econômicos, construídos através do Software Microsoft Office Excel. Para tanto foi realizada a caracterização da recessão econômica ocorrida no país através da análise de gráficos de barra do PIB real anual e as taxas de investimento no país no período de 2009 a 2019.

Foram examinados também os indicadores de desemprego, rendimento mensal médio real do trabalhador brasileiro, consumo de bens duráveis e o comportamento econômico do setor de serviços de reparo e manutenção. Essa análise foi realizada por meio da regressão através da utilização de linhas de tendências gráficas lineares, com dados secundários provenientes de Infográficos (2019), Alvarenga (2019) e por fim do Instituto Brasileiro de Geografia e Estatística (IBGE), que concentra uma grande gama de séries de dados disponíveis (IBGE, 2019).

A análise por regressão exibe a orientação de dados e analisa problemas de previsão por meio de linhas de tendência estatísticas. Essas técnicas de representação gráfica geralmente são utilizadas em análises técnicas por operadores de ações e para controles financeiros, pois permitem identificar as tendências do mercado, auxiliando na tomada de decisões. As linhas de tendência são retas traçadas a partir dos topos (máximos significativos) e fundos (mínimos significativos) de um gráfico, sendo necessária a existência de no mínimo três pontos de dados, 
para existência de um nível mínimo de coincidência. Desta forma, é possível inferir três tipos de linhas de tendência: ascendentes; descendentes; e estacionárias (NOGUEIRA, 2017).

\section{RESULTADOS E DISCUSSÃO}

\subsection{0 crescimento econômico e os investimentos}

Para que se torne possível a análise e mensuração da atividade econômica do país a Figura 2 apresenta o PIB real anual do ano de 2009 a 2018. Esse gráfico permite constatar o comportamento positivo de crescimento da produção total de bens e serviços no país entre os anos de 2010 e 2014, sendo o último o ano do período referido onde se começou sinalizar o cenário de recessão econômica que atingiria o país no ano seguinte.

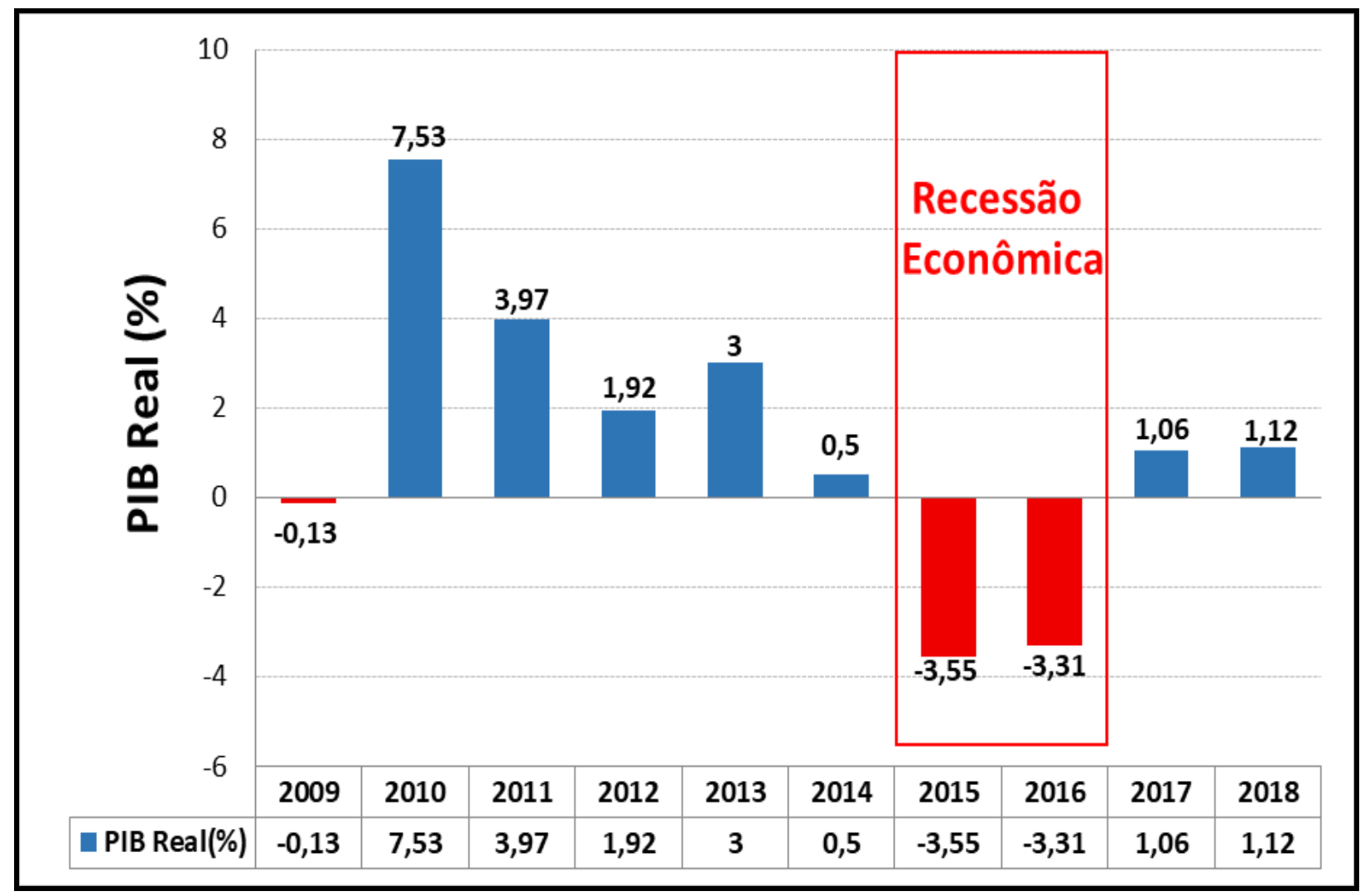

Fonte: Adaptado Infográficos, 2019.

Figura 2 - Produto Interno Bruno Real Anual nos últimos 10 anos (2009 a 2018)

Para o ano de 2014 o saldo final do PIB real foi pequeno, mas positivo, sendo que o primeiro e o quarto trimestre desse ano tiveram resultante negativa para o PIB. Sinalizada no gráfico entre os anos de 2015 e 2016 observa-se a retração econômica que atingiu o país, em que o PIB anual real resultou em -3,55\% e -3,31\%, conforme a Figura 2.

Desta forma, é possível observar a correta caracterização da crise econômica que ocorreu no país como resultado redução da produção do total de bens e serviços para o período entre os anos de 2015 e 2016. Considerando-se que o resultado geral de encolhimento das atividades econômicas para o referido período é possível observar ainda que a retomada do crescimento do PIB para os anos de 2017 e 2018 não obteve grande impactos para economia do país quando comparado aos períodos de crescimento caracterizados entre os anos de 2010 e 2013.

Sendo os investimentos realizados em um país um dos componentes da demanda agregada do PIB, para facilitar a comparação entre a taxa de investimento, o desemprego, a redução do 
consumo e por consequência a maior busca pelos serviços de manutenção e reparo dos bens duráveis, a Figura 3 apresenta gráfico que caracteriza a taxa de investimentos públicos e privados anuais no país em relação ao PIB para o período entre os anos de 2010 e 2018.

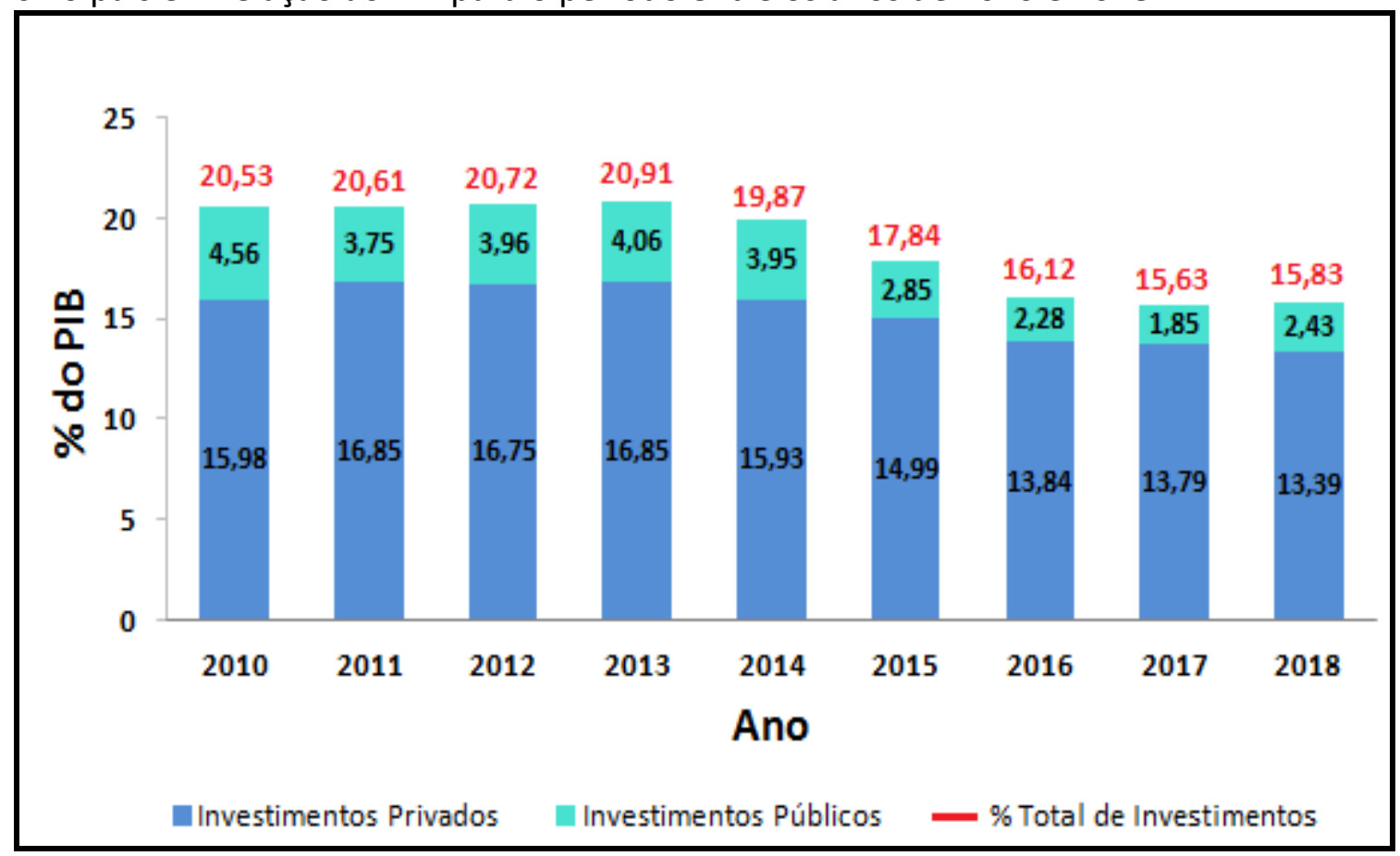

Fonte: Adaptado Alvarenga, 2019.

Figura 3 - Taxa de Investimento Anual em Relação ao PIB (2010 a 2018)

Ao analisar o gráfico da Figura 3 é possível inferir a manutenção da taxa de investimento total em relação ao PIB em crescimento para o período entre os anos de 2010 e 2013, nota-se a redução dos investimentos no país a partir do ano de 2014 com uma redução de aproximadamente $5 \%$ da taxa de investimentos públicos e privados em relação ao ano de 2013 . 0 percentual de queda do índice analisado mantém-se praticamente constante entre os anos de 2015 e 2016, de 10,2\% e 9,6\% respectivamente. É possível observar também que a taxa de investimento anual em relação ao PIB sofreu uma redução de 21,3\% do ano de 2014 para 2017.

A redução dos investimentos privados em uma região ocorre devido ao retorno financeiro inconsistente para as empresas externas ao país, com a falta de investimentos privados, reduz-se a produção de bens e serviços, por sua vez a coleta fiscal, impedindo também o incremento e manutenção dos investimentos de natureza pública.

\subsection{0 mercado de trabalho e as flutuações econômicas}

A redução dos investimentos no país acarreta na diminuição das atividades produtivas das organizações sejam elas de natureza pública ou privadas, isso gera a não necessidade de mão de obra, observando-se o aumento nas taxas de desocupação no país. De acordo com os dados de IBGE (2019e) foi possível construir o gráfico apresentado na Figura 4, em que os dados se referem ao período o ano de 2012 e o primeiro semestre de 2019, sendo apresentadas as taxas de desocupação anual no país em \% até o ano de 2018 e a média corrente para o primeiro semestre de 2019.

Observando-se o comportamento geral do gráfico da Figura 4 é possível constatar três períodos distintos. O primeiro período entre os anos de 2012 e 2014 onde as taxas de desocupação encontravam-se em média entre $7,1 \%$, sendo os valores mais baixos de taxas atingidos para o período total abrangido no gráfico. 0 segundo período sinalizado entre os anos de 
2015 e 2016 caracterizam o ponto de inflexão do gráfico, em que ocorre a elevação das taxas de desocupação no país, sendo o percentual de aumento do ano de 2014 para o de 2015 de $25 \%$, e do ano de 2015 para o de 2016 de $35,3 \%$.

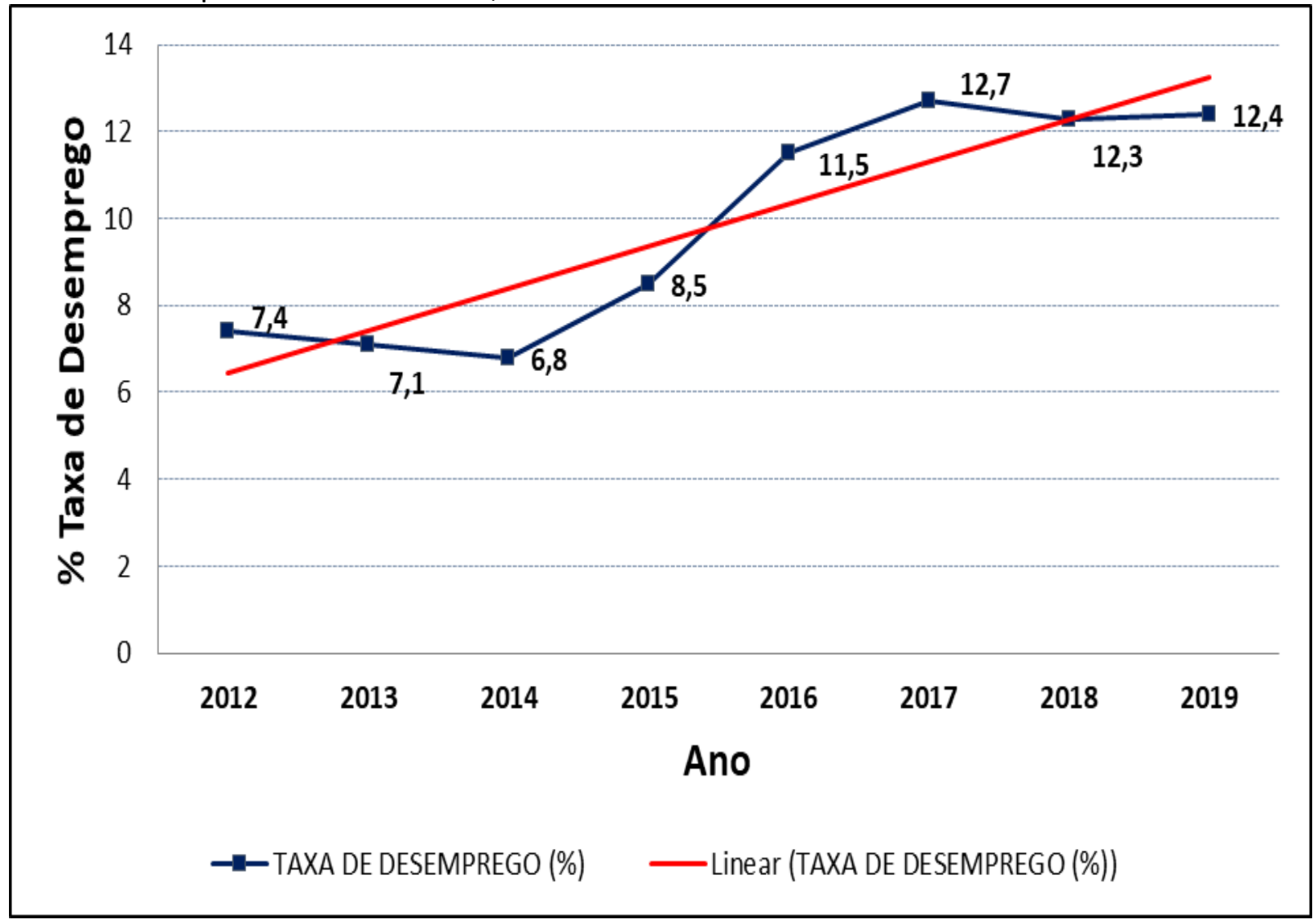

Fonte: IBGE, 2019e.

Figura 4 - Taxa de Desocupação Anual (2012 ao primeiro semestre de 2019)

O terceiro período distinto do gráfico ocorre entre os anos de 2017, 2018 e o primeiro semestre de 2019, nesse espaço de tempo as taxas de desocupação se estabilizam em valores elevados, alcançando uma média de $12,5 \%$ ao ano, que se comparada à média do período anterior à recessão econômica representam um acréscimo de 76 \% nas taxas de desocupação. Essa elevação abrupta das taxas de desocupação é demarcada principalmente pela regressão através linha tendência linear sinalizada no gráfico da Figura 4, observa-se pela inclinação da reta traçada que ocorreu o comportamento ascendente das taxas de desocupação para o período total analisado, demonstrando a variação simétrica das taxas de desocupação através da tendência linear traçada. Para o período compreendido entre os anos de 2014 e 2017 observa-se que a taxa de desocupação no país sofreu elevação de $86,8 \%$.

\subsection{Rendimento médio mensal do brasileiro}

O gráfico da Figura 5 foi construído com base na PNAD - IBGE, sendo o objeto o rendimento médio mensal real do trabalhador brasileiro. Ao examinar o referido é possível observar que a sua tendência linear possui também o comportamento ascendente, sinalizando crescimento do rendimento médio real mensal do trabalhador brasileiro entre os anos de $2012 \mathrm{e}$ 2019.

Comparando-se os gráficos das Figuras 4 e 5, observa-se que a curva do rendimento médio real mensal do brasileiro apresenta comportamento simétrico inverso ao da taxa de desocupação, isso permite inferir que conforme o desemprego reduz, o rendimento médio mensal do brasileiro 
aumenta, e conforme o desemprego aumenta, o rendimento médio mensal do brasileiro reduz. Essa observação permite comprovar o que foi descrito na "lei da oferta e procura" citada no referencial teórico.

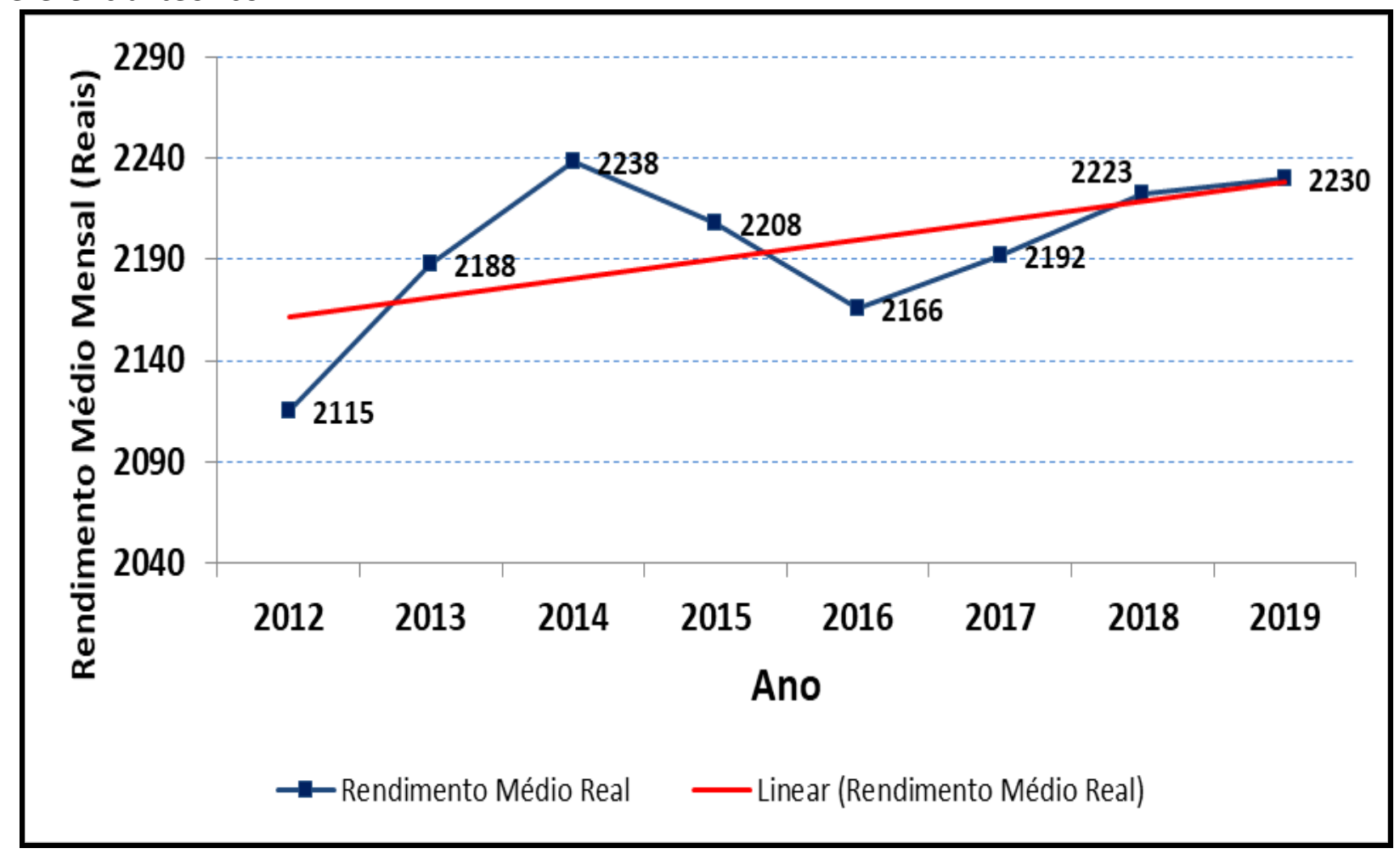

Fonte: IBGE, 2019d.

Figura 5 - Rendimento Médio Real Mensal Trabalhador Brasileiro do Setor Formal (de 2012 ao segundo semestre de 2019)

Analisando-se de forma percentual a evolução do rendimento médio mensal do trabalhador brasileiro para os anos de 2015 e 2016, ocorreu uma queda de 1,3\% no ano de 2015 em relação ao ano de 2014, e uma queda de 1,9 \% para o ano de 2016 em relação ao ano de 2015. Desta forma foi acumulada uma redução de $2,1 \%$ no rendimento médio mensal do brasileiro no período entre os anos de 2014 e 2017.

\subsection{Consumo de bens duráveis}

A estrutura de produção industrial tem por finalidade atender os mercados potenciais de consumo ao seu alcance, assim o gráfico da Figura 6 foi construído através dos dados de produção de bens duráveis no país para o período fevereiro de 2012 e julho de 2019, levantados através da PIM-PF do IBGE. Essa pesquisa fornece um Índice Mensal de Base Fixa calculado a partir da quantidade manufaturada e no preço de bens de consumo em comparação mensal. De acordo com (BRASIL, 2015), os índices mensais podem ser interpretados como médias ponderadas de relativos de quantidades cujos pesos são definidos pelo valor de cada produto, estimado a partir das quantidades e preços vigentes no mês anterior.

O gráfico da Figura 6 demonstra a tendência descendente da produção de bens duráveis no país caracterizada pela regressão de dados traçada no gráfico, observa-se que o delimitador para essa redução do consumo ocorreu principalmente para os índices sinalizados entre os anos de 2015 e 2016, como o mercado produtivo segue as necessidades da demanda da população, observa-se a redução do consumo de bens duráveis no país para o período abrangido no gráfico. Examinando o período pós-recessão econômica identificado no gráfico entre os anos de 2017 e 2019, observa-se que ocorreu o crescimento do consumo no ano de 2017 e sequente estagnação 
deste para os anos subsequentes. A média do Índice Mensal de Base Fixa para o ano de 2014 foi 94,95 e para o ano de 2017 foi de 75,28, assim entre os anos de 2014 e 2017 observa-se uma redução de $20,7 \%$ na produção de bens duráveis no país.

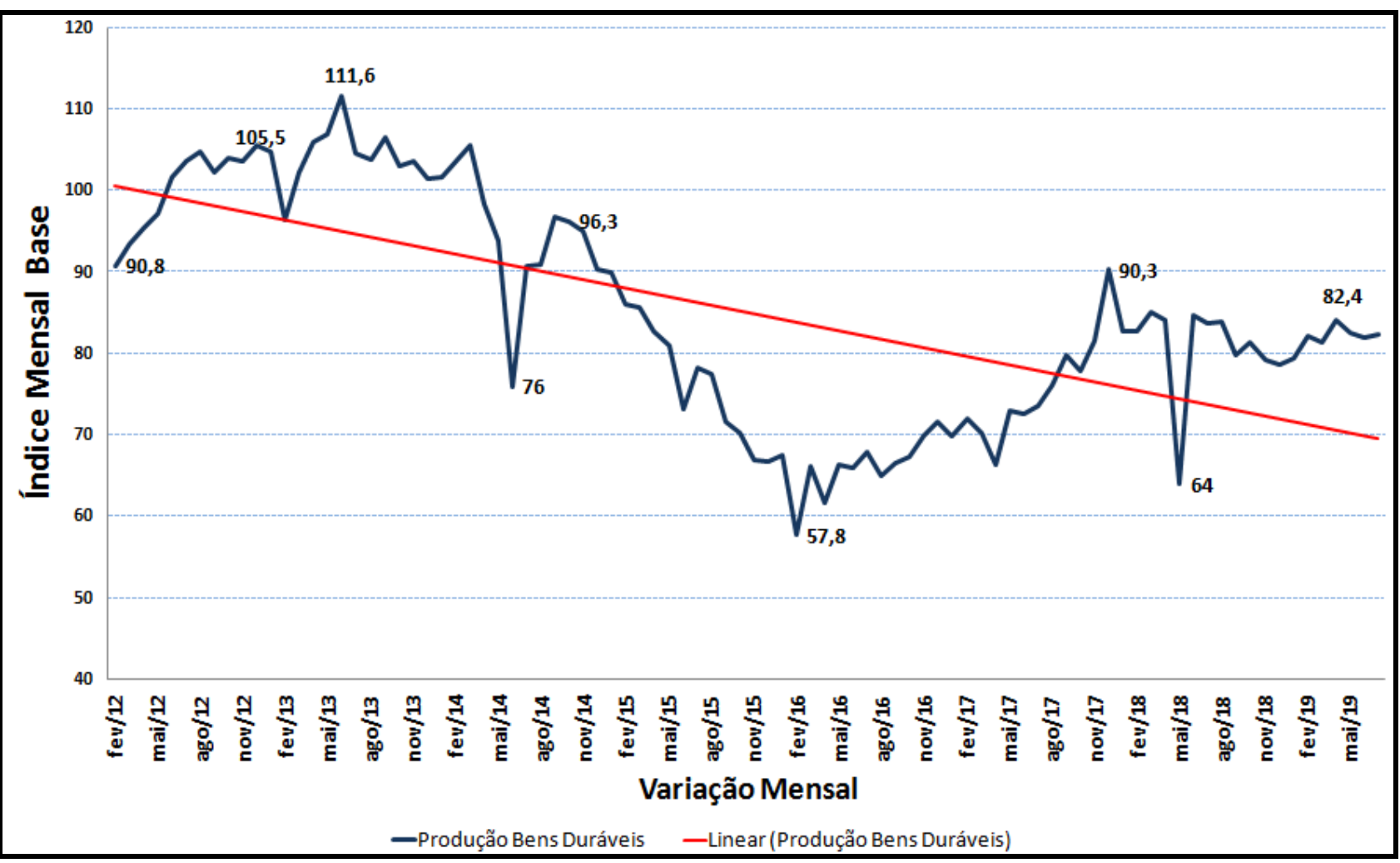

Fonte: IBGE, 2019b.

Figura 6 - Produção Mensal de Bens Duráveis (de 2012 ao primeiro semestre de 2019)

As características elencadas para o gráfico da Figura 6 demonstram que os brasileiros optaram por não trocar seus bens duráveis, sendo para tanto necessária a realização de maiores intervenções técnicas para a manutenção da operacionalidade destes.

\subsection{Comportamento do setor de serviços de reparo e manutenção}

Para a caracterização do aumento da procura por serviços de reparo e manutenção no país é necessário estudar a montante de movimentações financeiras setoriais neste mercado. Desta forma, foi construído o gráfico da Figura 7, que apresenta a receita líquida anual real de reparos para os setores de objetos pessoais e domésticos, equipamentos de informática e comunicação e veículos automotores.

Ao observar-se o comportamento geral das curvas traçadas no gráfico da Figura 7 é possível constatar que todas apresentam comportamento linear ascendente, a regressão construída demonstra a sua similaridade com as curvas originais de dados. O comportamento total do setor de reparos e manutenção apresentou um crescimento de $10,6 \%$ em sua receita líquida total para o período entre os anos de 2014 e 2017. Para o período total analisado no gráfico de 2007 a 2017, observa-se um crescimento expressivo do setor de cerca de $193 \%$.

Tornando-se a análise segmentada, observa-se que o setor de veículos automotores é o que apresenta participação mais significativa para o total da receita líquida para o período analisado, devido a seu montante movimentado. Esse setor apresentou uma pequena redução de 1,2\% do rendimento do ano de 2014 para 2015, em que ocorreu o início da crise econômica, mas 
este segmento passou a crescer no ano seguinte, aumentando sua receita líquida em 4,5\%. Ao analisar o período pré e pós-crise econômica (de 2014 a 2017) para o setor de reparos automotivos, observa-se um crescimento total de aproximadamente $13,1 \%$.

O segundo setor mais representativo esboçado no gráfico da Figura 7 foi o de reparo e manutenção de objetos pessoais e domésticos, com crescimento de $20,7 \%$ em sua receita líquida anual para o período entre 2014 e 2017. Ao observar a curva deste parâmetro traçado observa-se que é a que mais apresenta similaridade a linha de tendência delineada, estando ambos praticamente sobrepostos.

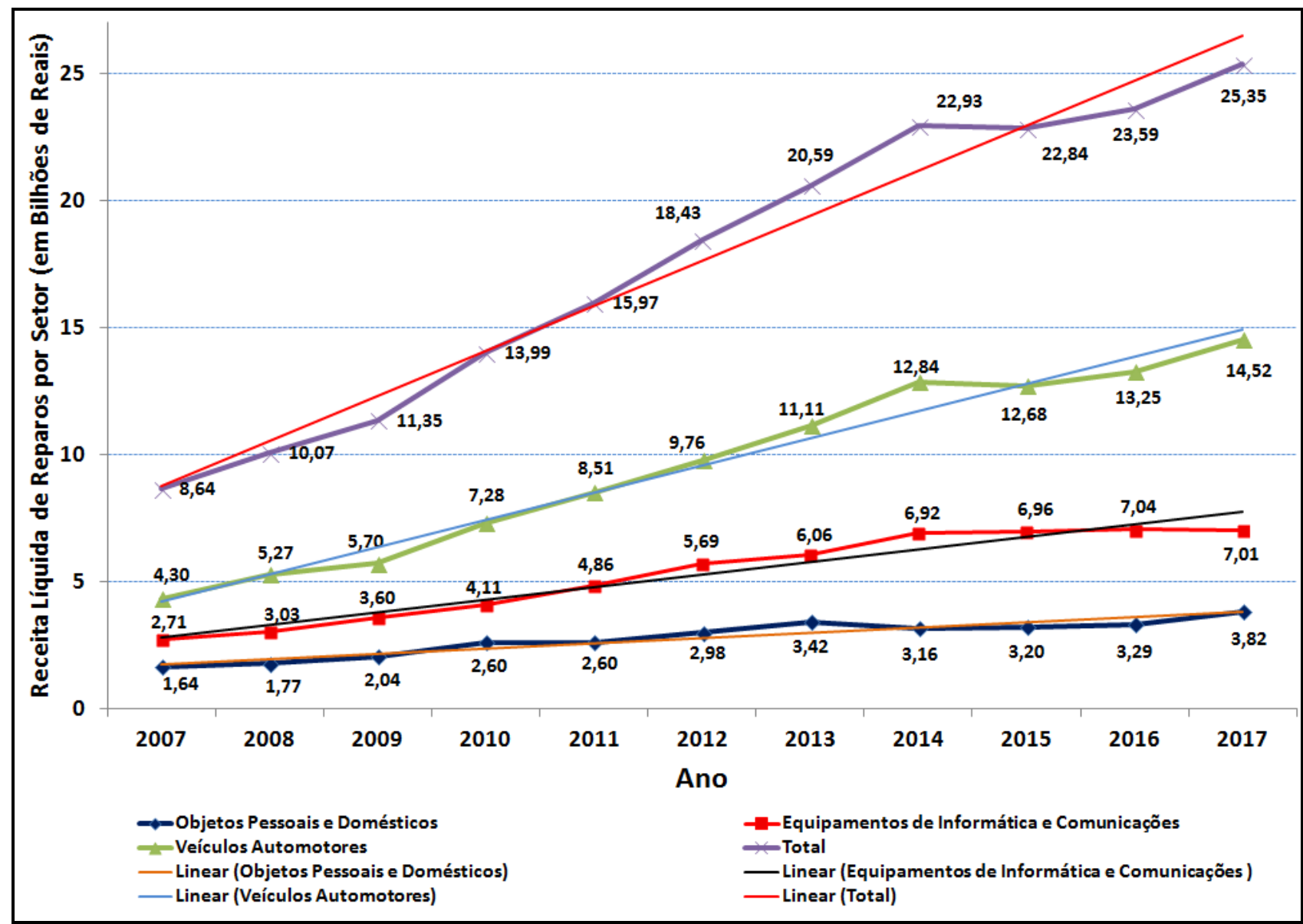

Fonte: IBGE, 2019g.

Figura 7 - Receita Líquida Real Anual de Reparos por Setor (2007 a 2017)

O setor que teve menor impacto para os serviços de reparo e manutenção foi o de equipamentos de informática e comunicações, demonstrando um crescimento de aproximadamente $1,4 \%$ para o período entre os anos de 2014 e 2017. Ao observar sua curva constata-se que mesmo no período da recessão econômica houve o aumento dos serviços deste setor. Em análise relativa observa-se que o crescimento desse setor não impacta o todo analisado de forma representativa devido a maioria dos produtos de informática e comunicação não favorecerem o reparo, pois muitas vezes o custo do reparo não é mais compensador do que adquirir um produto novo. 


\subsection{Síntese de resultados}

A análise de dados realizada permitiu inferir a situação geral e pormenorizada dos parâmetros examinados, para que seja possível obter um resumo das principais características levantadas foi construída a Tabela 2 que apresenta uma síntese dos resultados obtidos. Essa tabela foi construída elencando os fatores analisados, período, o valor de crescimento ou redução do parâmetro para o período delineado em porcentagem, a característica, e para os gráficos que foram analisados através das linhas de tendência é apresentado também o tipo da linha de tendência.

A partir da Tabela 2 é possível verificar a caracterização da crise econômica nos anos de 2015 e 2016 devido a retração do PIB. Os demais parâmetros analisados compreendem o período entre 2014 e 2017, 2014 foi o ano em que se deu os primeiros sinais que o país passaria por uma crise econômica, e 2017 por ser o ano após a caracterização da crise. Observa-se que para o período delineado Taxa de Investimento do PIB caiu cerca de $21,3 \%$, o que significa que não foram investidas grandes quantias em novos equipamentos e modernizações, devido aos retornos financeiros inconsistentes causados pela crise.

Tabela 2 - Síntese de Resultados da Análise de Dados

\begin{tabular}{|c|c|c|c|c|}
\hline FATOR ANALISADO & PERÍODO & VALOR EM \% & CARACTERÍSTICA & $\begin{array}{l}\text { LINHA DE TENDÊNCIA } \\
\text { LINEAR }\end{array}$ \\
\hline \multirow{2}{*}{$\begin{array}{c}\text { Produto Interno Bruto } \\
\text { PIB }\end{array}$} & 2015 & $-3,55$ & & \multirow{3}{*}{ Não Possui } \\
\hline & 2016 & $-3,31$ & Requçao & \\
\hline $\begin{array}{c}\text { Taxa de Investimento } \\
\text { do PIB }\end{array}$ & \multirow{5}{*}{2014 a 2017} & $-21,3$ & Redução & \\
\hline Taxa de Desocupação & & $+86,8$ & Aumento & Ascendente \\
\hline $\begin{array}{c}\text { Rendimento Médio } \\
\text { Anual Trabalhador } \\
\text { Brasileiro }\end{array}$ & & $-2,1$ & Redução & Descendente \\
\hline $\begin{array}{l}\text { Consumo (Produção) } \\
\text { de Bens Duráveis }\end{array}$ & & $-20,7$ & Redução & Descendente \\
\hline $\begin{array}{l}\text { Rendimento Anual } \\
\text { Líquido Setor de } \\
\text { Serviços de Reparo e } \\
\text { Manutenção }\end{array}$ & & $+10,6$ & Aumento & Ascendente \\
\hline
\end{tabular}

Fonte: Autores, 2019.

A Tabela 2 apresenta também os dados da taxa de desocupação para o período entre 2014 e 2017 , onde se verifica o aumento de $86,8 \%$ na desocupação dos brasileiros, reflexo da redução das atividades das empresas públicas e privadas no país. Com a elevação do desemprego a tendência é o rendimento médio do trabalhador cair, e como apresentado ocorreu a redução de $2,1 \%$ no rendimento médio anual do trabalhador brasileiro no período entre 2014 e 2017 . 0 consumo de bens duráveis no país depende das condições de trabalho e remuneração do trabalhador, como apresentado na Tabela 2, houve a redução de $20,7 \%$ na produção de bens duráveis no país para o período entre 2014 e 2017.

Como demonstrado, as consequências negativas da crise econômica sobre a taxa de desocupação e o rendimento do trabalhador culminaram com a redução do consumo de bens duráveis pelas famílias brasileiras. Esse fato favoreceu o fortalecimento do mercado de reparação e manutenção no país, sendo a tendência total obtida para o crescimento com incremento de 
aproximadamente $10,6 \%$ na receita operacional líquida do setor entre os anos de 2014 e 2017 . 0 que foi caracterizado principalmente pelo setor de reparo de objetos pessoais e domésticos que apresentou um crescimento de $20,7 \%$ e pelo setor de reparo veículos automotores com $13,1 \%$ de expansão para o período destacado.

\section{CONCLUSÃO}

O comportamento de mercados econômicos segmentados depende de diversos fatores envolvidos, ao estudar esses agentes de forma associativa é possível delinear tendências de desempenho do setor analisado. O objetivo deste trabalho de analisar os efeitos da crise econômica no Brasil para o setor de serviços de reparo e manutenção foi alcançado de maneira satisfatória, pois foi possível nortear o comportamento desse mercado relacionando-o com os seguintes fatores: taxa de desocupação, rendimento do trabalhador, consumo de bens duráveis e a receita operacional líquida de serviços de reparo e manutenção de bens duráveis.

Para compreensão dos agentes econômicos que permitem identificar a ocorrência de uma retração econômica o trabalho introduziu conceitos que permitem entender a dinâmica de análise do PIB de uma região, bem como a influência da taxa de investimento em relação ao PIB e seus efeitos sobre o mercado de consumo de bens duráveis.

Alinhados a análise do PIB, a taxa de desocupação e o rendimento do trabalhado demonstraram comportamento inverso através da inferência gráfica, ou seja, quando uma tende a ter atitude ascendente a outro tem tendência descendente, e vice-versa. Assim, em tempos de recessão econômica, o desemprego tende a crescer e a remuneração do trabalhador tende a cair, culminando com a redução de sua capacidade de consumo de bens duráveis, demonstrada por meio da tendência linear descendente gráfica.

A redução do consumo de bens duráveis favoreceu o setor de reparo e manutenção destes, o que foi demonstrada através de análise de tendência gráfica e percentual, por meio dos resultados do setor. Assim, o exame do encadeamento relativo dos fatores propostos no trabalho permitiu delinear um escopo para o entendimento do processo de comportamento do mercado de manutenção e reparo de bens duráveis na economia nacional.

Este estudo não objetivou esgotar o assunto ou torná-lo conclusivo, mas sim fornecer uma caracterização comportamental de um segmento de mercado frente a uma crise econômica. Como possibilidades de trabalhos futuros, propõe-se analisar outros segmentos de mercado de prestação de serviços em períodos de recessão econômica, como o setor de transportes, imobiliário, correio, administrativos e serviços para família.

\section{REFERÊNCIAS}

ALVARENGA, Darlan. Taxa de investimentos é a menor em mais de $\mathbf{5 0}$ anos e fica mais dependente do setor privado. 19 jul. 2019. Disponível em:

https://g1.globo.com/economia/noticia/2019/07/19/taxa-de-investimentos-e-a-menor-em-maisde-50-anos-e-fica-mais-dependente-do-setor-privado.ghtml. Acesso: em 20 set 2019.

ANDRADE, R. L. M. M.; MORAIS, F. F.. A reforma das normas trabalhistas em meio à crise econômica no Brasil. Revista Saberes da Amazônia, Porto velho, v. 2, n. 5, 2017.

BASTOS, E. K. X.; ARAUJO, B. C.. Variações na renda real não captadas pelo PIB: efeito termos de troca e efeito preços relativos entre comerciáveis e não comerciáveis: Brasil, 1991-2016. Instituto de Pesquisa Econômica Aplicada (IPEA), Brasília, 2017. 
BRASIL. Ministério do Planejamento, Orçamento e Gestão. Instituto Brasileiro de Geografia e Estatística. Relatório Metodológico - Indicadores Conjunturais da Indústria. Brasília, 2015.

CALARGE, F. A. et al. Análise e avaliação da qualidade de serviços internos com foco na manutenção de utilidades em uma empresa de manufatura. Production, São Paulo, v. 26, n. 4, p. 724-741, 2016.

CARVALHO, David Ferreira; CARVALHO, André Cutrim. Crise financeira, recessão e risco de depressão no capitalismo globalizado do século XXI. Cadernos CEPEC, v. 1, n. 1-6, 2019.

EARP, F. S.; PAULANI, L. M.. Mudanças no consumo de bens culturais no Brasil após a estabilização da moeda. Nova Economia, v. 24, n. 3, p. 469-490, 2014.

FEVEREIRO, José Bruno. Decomposição da taxa de crescimento do PIB pelo lado da demanda: uma metodologia alternativa.Carta de Conjuntura - Instituto de Pesquisa Econômica Aplicada (IPEA), Rio de Janeiro, 2016.

INFOGRÁFICOS. PIB do Brasil: Histórico e evolução em gráficos. Brasil, 2019. Disponível em: https://infograficos.gazetadopovo.com.br/economia/pib-do-brasil/. Acesso: em 07 set 2019.

INSTITUTO BRASILEIRO DE GEOGRAFIA E ESTATíSTICA (IBGE). Frota de Veículos. Brasília, 2019. Disponível em: https://cidades.ibge.gov.br/brasil/pesquisa/22/0?ano=2017. Acesso em: 13 set. 2019.

INSTITUTO BRASILEIRO DE GEOGRAFIA E ESTATÍ́STICA (IBGE). Pesquisa Industrial Mensal Produção Física (PIM-PF). Brasília, 2019. Disponível em:

https://www.ibge.gov.br/estatisticas/economicas/industria/9296-pesquisa-industrial-mensalproducao-fisica-regional.html?edicao=19267\&t=series-historicas. Acesso em: 15 set. 2019.

INSTITUTO BRASILEIRO DE GEOGRAFIA E ESTATÍ́stICA (IBGE). Pesquisa Nacional por Amostra de Domicílios Contínua (PNAD) - Características Gerais dos Domicílios. Brasília, 2019. Disponível em: https://www.ibge.gov.br/estatisticas/sociais/populacao/17270-pnad-

continua.html?edicao=24437\&t=resultados. Acesso em: 10 set. 2019.

INSTITUTO BRASILEIRO DE GEOGRAFIA E ESTATÍ́sTICA (IBGE). Pesquisa Nacional por Amostra de Domicílios Contínua (PNAD) - Rendimento Médio Real. Brasília, 2019. Disponível em: https://sidra.ibge.gov.br/tabela/5442. Acesso em: 10 set. 2019.

INSTITUTO BRASILEIRO DE GEOgRAFIA E ESTATístICA (IBGE). Pesquisa Nacional por Amostra de Domicílios Contínua (PNAD) - Taxa de Desocupação. Brasília, 2019. Disponível em: https://www.ibge.gov.br/estatisticas/sociais/trabalho/9173-pesquisa-nacional-por-amostra-dedomicilios-continua-trimestral.html?t=resultados. Acesso em: 08 set. 2019.

INSTITUTO BRASILEIRO DE GEOGRAFIA E ESTATÍSTICA (IBGE). Produto Interno Bruto (PIB). Brasília, 2019. Disponível em: https://www.ibge.gov.br/explica/pib.php. Acesso em: 07 set. 2019.

INSTITUTO BRASILEIRO DE GEOGRAFIA E ESTATÍSTICA (IBGE). Resultados dos Serviços de Manutenção e Reparação. Brasília, 2019. Disponível em: https://sidra.ibge.gov.br/tabela/2675. Acesso em: 13 set. 2019. 
INSTITUTO DE PESQUISA ECONÔMICA APLICADA (IPEA). Indicador Ipea de Consumo Aparente de Bens Industriais. Brasília, 2019. Disponível em: http://www.ipea.gov.br/cartadeconjuntura/index.php/tag/indicador-de-consumo-aparenteindustrial/. Acesso em: 20 set. 2019.

INSTITUTO DE PESQUISA ECONÔMICA APLICADA (IPEA). Produto Interno Bruto (PIB) Real. Brasília, 2019. Disponível em: http://www.ipeadata.gov.br/ExibeSerie.aspx?serid=38414. Acesso em: 07 set. 2019.

MATTOSO, Jorge. O Brasil desempregado: como foram destruídos mais de 3 milhões de empregos nos anos 90. São Paulo: Ed. Perseu Abramo, 2000.

MELO, H. P. et al. O setor de serviços no Brasil: uma visão global - 1985/95. Instituto de Pesquisa Econômica Aplicada (IPEA). Rio de Janeiro, 1998.

MONTALI, Lilia. Rearranjos familiares de inserção, precarização do trabalho e empobrecimento. Anais ENAP-ABEP, p. 1-20, 2016.

MOULIN, Rodrigo. $O$ direito do consumidor após o fim da garantia. São Paulo, 2015. Disponível em: https://marcellobenevides.com/direito-consumidor-apos-fim-garantia/. Acesso: em 07 set 2019.

NOGUEIRA, Vasco. Como usar linhas de tendência para previsão de dados. Portugal, 2017. Disponível em: https://www.portal-gestao.com/artigos/7898-como-usar-linhas-detend\%C3\%AAncia-para-previs\%C3\%A3o-de-dados.html. Acesso: em 20 set 2019.

NUNES, C. J.; FRANÇA, R. A.; REIS, C. P.. Rotatividade e absenteísmo nas indústrias de pequeno e médio porte de São Sebastião do Paraíso, Estado de Minas Gerais. Revista de Iniciação Científica da Libertas, v. 3, n. 2, 2016.

PAULA, Luiz Fernando de; PIRES, Manoel. Crise e perspectivas para a economia brasileira. Estudos Avançados, v. 31, n. 89, p. 125-144, 2017.

POCHMANN, Marcio. Desempenho econômico conjuntural e a situação recente do trabalho no Brasil. Revista do Núcleo de Estudos de Economia Catarinense (NECAT), v. 7, n. 13, p. 12-28, 2018.

POCHMANN, Marcio. Políticas de Ajuste Econômico e Desemprego no Brasil Metropolitano nos Últimos 35 Anos. Mercado de trabalho: qualificação, emprego e políticas sociais. Fortaleza, p. 1126, 2016.

RECESSÃO. Merriam Webster Online Dictionary, 18 jun. 2019. Disponível em: https://www.merriam-webster.com/dictionary/recession. Acesso em 07 set. 2019.

ROSSI, P.; MELLO, G.. Componentes macroeconômicos e estruturais da crise brasileira: o subdesenvolvimento revisitado. Brazilian Keynesian Review, v. 2, n. 2, p. 252-263, 2017. 